\title{
Entomopathogens Isolated from Invasive Ants and Tests of Their Pathogenicity
}

\author{
Maria Fernanda Miori de Zarzuela, ${ }^{1}$ Luis Garrigós Leite, ${ }^{2}$ \\ José Eduardo Marcondes, ${ }^{2}$ and Ana Eugênia de Carvalho Campos ${ }^{3}$ \\ ${ }^{1}$ Centro de Estudos de Insetos Sociais, Universidade Estadual Paulista, Avenida 24-A, 1515, 013506-900 Rio Claro, SP, Brazil \\ ${ }^{2}$ Laboratório de Controle Biológico, Instituto Biológico, Rodovia Heitor Penteado, Km 3, 13092-593 Campinas, SP, Brazil \\ ${ }^{3}$ Unidade Laboratorial de Referência em Pragas Urbanas, Instituto Biológico, Avenida Conselheiro Rodrigues Alves, 1252, \\ 04014-002 São Paulo, SP, Brazil
}

Correspondence should be addressed to Ana Eugênia de Carvalho Campos, anaefari@biologico.sp.gov.br

Received 5 April 2012; Revised 20 June 2012; Accepted 21 June 2012

Academic Editor: Ai-Ping Liang

Copyright (๑) 2012 Maria Fernanda Miori de Zarzuela et al. This is an open access article distributed under the Creative Commons Attribution License, which permits unrestricted use, distribution, and reproduction in any medium, provided the original work is properly cited.

\begin{abstract}
Some ant species cause severe ecological and health impact in urban areas. Many attempts have been tested to control such species, although they do not always succeed. Biological control is an alternative to chemical control and has gained great prominence in research, and fungi and nematodes are among the successful organisms controlling insects. This study aimed to clarify some questions regarding the biological control of ants. Invasive ant species in Brazil had their nests evaluated for the presence of entomopathogens. Isolated entomopathogens were later applied in colonies of Monomorium floricola under laboratory conditions to evaluate their effectiveness and the behavior of the ant colonies after treatment. The entomopathogenic nematodes Heterorhabditis sp. and Steinernema sp. and the fungi Beauveria bassiana, Metarhizium anisopliae, and Paecilomyces sp. were isolated from the invasive ant nests. M. floricola colonies treated with Steinernema sp. and Heterorhabditis sp. showed a higher mortality of workers than control. The fungus Beauveria bassiana caused higher mortality of M. floricola workers. However, no colony reduction or elimination was observed in any treatment. The defensive behaviors of ants, such as grooming behavior and colony budding, must be considered when using fungi and nematodes for biological control of ants.
\end{abstract}

\section{Introduction}

Among social insects, some ant species have adapted to disturbed environments in urban areas. In Brazil, it is estimated that from 2000 identified species of ants, 50 species are pests causing losses in rural and urban areas and damage to public health [1]. Some of them, native or exotic to the country, have the status of invasive species.

Biological invasion occurs when a species has competitive advantage, natural obstacles to deter their proliferation are not present, disperses quickly, and invades new areas, becoming a dominant population [2]. In such cases, control measures must be defined in order to minimize problems associated to the invading species. Integrated pest management (IPM) has been used as rational pest control practices and biological control is among the several used tools [3].
The recognition of biological control agents in the field is essential for successful use of exotic natural enemies [3] such as entomopathogens, parasitoids, and predators [4].

Each natural enemy offers advantages for the control of different pests, but some of them are better used on urban pests, such as the entomopathogens, including fungi and nematodes. Human tolerance to these natural enemies must be considered [4]. Therefore, when the problem faced is at urban ant species, caution is advised.

Ant behavioral adaptations can cause failures of control measures using natural enemies. Thus, an understanding of ant defenses is necessary when biological control measures are used [5]. Several studies have been conducted in order to test different natural enemies of ants, especially on the Brazilian native fire ants, Solenopsis invicta [6-12]. In order to contribute to the searches of natural enemies of ants and 
their effects on these insects, this study evaluated the presence of entomopathogenic fungi and nematodes inside ant invasive species nests and their pathogenicity compared to entomopathogenic fungi deposited in a scientific collection.

\section{Materials and Methods}

2.1. Entomopathogens Isolated from Ant Invading Species Nests in Brazil. Soil sample was collected from invasive ant nests and from the soil three meters away from them (control soil samples). Samples were taken from 10 to $15 \mathrm{~cm}$ deep in the soil, set in plastic bags, and processed in the laboratory. Ants were discarded.

Collections were made in 70 localities in the states of São Paulo, Minas Gerais, Rio Grande do Sul, Mato Grosso do Sul, and Rio de Janeiro. Samples were conducted in those places where invading species were present. In this way, collections were not equally distributed in all states.

2.2. Entomopathogenic Nematode Isolation. Soil samples were individually placed in vials $(600 \mathrm{~mL})$ with five Galleria mellonella (Lepidoptera: Pyralidae) larvae that were used as baits for the entomopathogenic nematodes possibly present in the samples. Water was added into the vials in order to keep enough moisture for the nematodes reach the larvae. Vials were closed and kept under environment temperature and 12-hour photophase.

After one week, dead G. mellonella larvae were transferred to White traps [13] in order to isolate and identify the nematodes.

2.3. Entomopathogenic Fungi Isolation. One gram of the same soil samples for nematode isolation was separated to isolate entomopathogenic fungi. An aliquot of water corresponding to $100 \mathrm{x}$ the soil weight was added and the solution was stirred on a Vortex. Serial dilutions were prepared to obtain a $1: 100$ dilution. From the $10^{-2}$ dilution, $0.1 \mathrm{~mL}$ was removed in a biological safety cabinet and inoculated on the surface of a selective medium in a Petri dish and spread with a Drigalsky handle. The Petri dishes were incubated inverted at $27^{\circ} \mathrm{C} \pm 1^{\circ} \mathrm{C}$. The growth and sporulation of the fungi were assessed at 7 and 15 days after inoculation. Once the presence of fungi in the Petri dish was confirmed, it was transferred to another Petri dish containing potato dextrose agar medium in order to ensure isolation of the pathogen free of contaminants.

Isolated fungi were deposited as pure conidia, in $1.5 \mathrm{~mL}$ Eppendorf tubes, and placed in freezer at $-12^{\circ} \mathrm{C}$ for later application on ant colonies for efficacy tests. The isolated fungi were deposited at the Entomopathogenic Collection "Oldemar Cardim de Abreu" from Instituto Biológico, Campinas, Brazil.

2.4. Susceptibility of Colonies of Monomorium floricola to the Entomopathogens in Laboratory Conditions. Colonies of M. floricola (Hymenoptera: Formicidae) maintained at the Instituto Biológico Insectarium were used in bioassays to assess their susceptibility to entomopathogens isolated previously and to the entomopathogens deposited in the Entomopathogenic Collection "Oldemar Cardim de Abreu." M. floricola was chosen for the control bioassay once it is one of the main tramp ant species in Brazil and because its rearing methodology is well established in the laboratory.

2.5. Colonies of Monomorium floricola. Colonies used for nematode and fungus bioassays consisted of nest cells prepared with Petri dishes $(5 \mathrm{~cm}$ diameter and $1 \mathrm{~cm}$ deep) with the covers painted in black to reduce the intensity of light. Lateral openings were provided to permit ant entrance and exit. Petri dish bottoms were filled with plaster to form a cavity in the center. Two to three thousand ant workers, at least five ergatoid gynes (in $M$. floricola intermediate forms between worker and queen, with a spermatheca, typically substitute the queens for reproduction) and ca. $3 \mathrm{~cm}^{2}$ of brood (eggs, larvae, and pupae) were placed into the Petri dish. The colonies were then individually placed in the center of a plastic tray $(30 \times 26 \times 8 \mathrm{~cm})$, coated with Teflon 30 (Dupont) to avoid ant escaping. Colonies were maintained in a controlled room ( 25 to $28^{\circ} \mathrm{C}$ and 12-hour photophase), fed three times a week with Tenebrio molitor (Coleoptera: Tenebrionidae) larvae, water, and water/honey $(1: 1)$.

\subsection{Susceptibility to Entomopathogenic Nematodes}

2.6.1. Tested Nematodes. Tested nematodes are listed in Table 1 and belong from the Entomopathogen Collection "Oldemar Cardim de Abreu" from the Biological Institute, Campinas, Brazil. Such nematodes have been already tested as biological control for insects of agricultural importance, with established efficacy, but their use as biological control for urban pest ants was still unknown.

Nematodes isolated from ant nests were not used in the bioassays, because we could not rear them in laboratory conditions. They were sensible to manipulation and we did not have success in propagating any of them in vitro.

2.6.2. Bioassays. Five $M$. floricola colonies were used for each nematode isolate, besides the control group, totalizing 15 colonies. The nematodes were prepared in an aqueous suspension containing 5,600 infective juveniles (IFs)/mL (this concentration was higher than that for applications in other insect pests). An aliquot of $2 \mathrm{~mL}$ of the suspension was applied with a pipette directly on the colony. Mortality assessments were made daily during the first ten days, and three times a week until the end of the bioassays (33 days). Dead ants were removed with a brush and placed in Petri dishes with moistened filter paper and immediately stored in B.O.D. chamber at $25^{\circ} \mathrm{C}$ for confirmation of the cause of the death. In the case of confirmed nematode infection, these nematodes would leave the body of ants and would be found on the filter paper. The emerging nematodes were collected and deposited in plastic cups with a thin layer of water and placed in B.O.D. chamber at $18^{\circ} \mathrm{C}$ before identification.

The general conditions of the treated colonies were evaluated weekly using the same methodology proposed by Jacob [14], including rating the amount of brood, observations on 
TABle 1: Nematodes belonging to the Entomopathogen Collection “Oldemar Cardim de Abreu” Instituto Biológico, Campinas, Brazil.

\begin{tabular}{lccc}
\hline Isolate & Nematode & Origin & Collection site \\
\hline IBCB 02 & Steinernema carpocapsae & Soil sample & Flórida, EUA \\
IBCB 24 & Heterorhabditis amazonensis & Sphenophorus levis larvae & Piracicaba, SP \\
\hline
\end{tabular}

which immature forms were present, presence of alive brood and males, number of ergatoid gynes, and the size of the colony. Such observations were recorded using the following scales: for the amount of brood a value 0 represented absence of brood; 1 little brood; 2 for medium amount of brood, and 3 for large amount of brood present, compared to the initial $3 \mathrm{~cm}^{2}$ of brood. Types of immature forms were evaluated separately, due the importance of a healthy brood complement in growing colonies and to better characterize the effects of entomopathogens on the colonies. Colonies received a rate of $\mathrm{N}$ if brood was absent, $\mathrm{E}$ if egg was present; $\mathrm{L}$ if larvae were present and $\mathrm{P}$ if pupae were present. For quantitative analysis of brood presence, colonies were rated as 0 if brood was absent; 1 if only one immature life stage was present; 2 if two immature life stages were present and 3 if all three immature life stages were present.

The presence (1) or absence (0) of reproductive brood, males and ergatoid gynes were also rated because it provides important information on colony health. The production of sexual forms represents an attempt to perpetuate the colony when conditions become unfavorable.

Colony size was rated as 3 for colonies with normal sizes; 2 for colonies with small size; 1 if colonies showed large decrease in comparison to control colonies; 0 if complete colony death was observed.

\subsection{Susceptibility to Entomopathogenic Fungi}

2.7.1. Tested Fungi. The fungi selected for testing are shown in Table 2. The isolates from the Entomopathogen Collection "Oldemar Cardim Abreu" were selected because of known efficacy in controlling other pests and for having been isolated from other insects, not ants. The other species of fungi were isolated from invasive ant nests sampled in this study.

2.7.2. Bioassays. As in the bioassay with nematodes, five colonies of M. floricola were used for each combination of conidial concentration of fungal isolate, and for the control group, with a total of 65 colonies.

The fungi were grown on Petri dishes containing potato dextrose agar medium [15]. After inoculation, Petri dishes were transferred to B.O.D. chamber at $27^{\circ} \mathrm{C}$ and 12-hour photophase for a period of 12 days. After this period, the conidia were removed by scraping with a nickel-chromium loop and suspended in sterile distilled water containing the spreading agent (Tween 80 ) at $0.1 \%$. Conidia were counted using a Neubauer chamber under an optical microscope Zeiss, with 40x magnification.

Dilutions were made to obtain the concentrations normally applied on other insect bioassays $\left(1.0 \times 10^{7}\right.$ and $1.0 \times$
$10^{8}$ conidia per $\mathrm{mL}$ ). Each tested colony received $1 \mathrm{~mL}$ of each fungi concentration. The fungi were applied with a manual sprayer designed for small surfaces and mounted at a height of $20 \mathrm{~cm}$ from the colony. During fungal application, all individuals (ergatoid gynes, workers, and brood) were sprayed by a fine mist of the conidial suspension with entomopathogenic fungi. Control colonies received the similar application, but with water only.

Mortality and colony health evaluations were conducted as for the nematode bioassay, including the weekly evaluations for colony general conditions. Dead ants were removed from the colony tray with the help of a moistened brush, placed in Petri dishes with a wet piece of cotton, and placed in a B.O.D. chamber at $15^{\circ} \mathrm{C}$ for 15 days for cause of death confirmation. If fungal growth was observed exiting the dead ant bodies infection was confirmed.

2.8. Data Analysis. Data on presence of entomopathogens in nest and control soil samples were compared. Each one of the 70 collection pairs (nests $\times$ control soil samples) was analyzed and four possible outcomes were recorded: (a) isolation in either nest or control soil sample, (b) entomopathogens only in the nests, (c) entomopathogens only in the control soil samples, and (d) entomopathogens in both samples. From these four outcomes, we could analyze if nematodes or fungi were present equally using the McNemar Test. This analysis was done separately for fungi and nematodes and later for each isolate. Isolated nematode and fungus species and their respective frequencies were analyzed by the Exact Fisher Test (for samples lesser than five) and by the Pearson Qui Square Test.

In order to analyze $M$. floricola mortality in the laboratory bioassays an analysis of variance with repeated measurements (ANOVA) was used, followed by the post doc Tukey Test for multiple comparisons among the groups, and the Profile Test for time comparisons. The rank transformation was used to obtain variance homogeneity and normal distribution. A 0.05 significance level was used for all statistical tests.

\section{Results}

3.1. Entomopathogens Isolated from Invasive Ants and Tests of Their Pathogenicity. This work reports for the first time the isolation of entomopathogens inside Linepithema spp., Nylanderia fulva and Brachymyrmex pictus nests. We also isolated entomopathogens from Solenopsis spp. as other authors have already registered.

From 70 samples, only 61 were used for analyzing the collected data, once the McNemar test only permits analysis with paired samples (nest and soil control samples). 
TABLE 2: List of tested fungi on Monomorium floricola colonies under laboratory conditions.

\begin{tabular}{lccc}
\hline Isolate & Fungi & Origin & Collection site \\
\hline $\mathrm{Bb} 66^{1}$ & Beauveria bassiana & Hypothenemus hampei & São José de Rio Pardo (São Paulo) \\
$\mathrm{Ma} 425^{1}$ & Metarhizium anisopliae & Larvae & Iporanga (São Paulo) \\
$\mathrm{P} 405^{1}$ & Paecilomyces sp. & Larvae & Espiro Santo do Pinhal (São Paulo) \\
$\mathrm{Bb} 25$ & Beauveria bassiana & Solenopsis sp. nest & São Paulo (São Paulo) \\
$\mathrm{Ma} 16$ & Metarhizium anisopliae & Solenopsis sp. nest & Corumbá (Mato Grosso do Sul) \\
$\mathrm{P} 40$ & Paecilomyces sp. & Solenopsis sp. nest & São Paulo (São Paulo) \\
\hline
\end{tabular}

${ }^{1}$ Isolates from the Entomopathogen collection “Oldemar Cardim de Abreu” from Instituto Biológico, Campinas, Brazil. IBCB 66 = Bb66, IBCB 425 = Ma 425, and IBCB $405=$ P 405 .

Thus, samples that were accidentally lost led to removal of the paired sample from the analysis. A greater number of entomopathogens was isolated from soil control samples, $49.2 \%$ (3), compared to $34.4 \%$ ant sample nests (21) $(P=$ $0.013)$.

Higher nematode frequency was found inside Linepithema spp., B. pictus and N. fulva when they were grouped together (4 nests $=30.8 \%)$ compared to Solenopsis spp. alone ( 1 nest $=1.79 \%)$. Nematodes were not found in $98.2 \%$ (55) Solenopsis spp. nests and 69.2\% (9) other ant species nests grouped together. The Exact Fisher Test showed significance for nematode isolated from the group of other species then Solenopsis spp. $(P=0.004)$.

Similar results were recorded for the isolated fungi. A higher frequency of fungi isolated from grouped species was found $(8$ nests $=72.7 \%)$ compared to Solenopsis spp. (14 nests $=27.5 \%),(P=0.012)$.

3.2. Nematode Isolation. The only nematode species isolated from ant nests, corresponding to $7.3 \%$ of the total samples, was Steinernema spp. On soil samples Heterorhabditis and Steinernema were isolated, with a higher frequency of Steinernema sp., $8.7 \%$. The frequency of Heterorhabditis sp. was $2.9 \%$. Nematodes were not found in $88.4 \%$ of the samples.

Occurrence of nematodes inside ant nests and in soil control samples was low. Unfortunately the limited data do not allow complete picture of the role of nematodes inside ant colonies.

From the 70 original samples, two were accidently lost. In this way 68 paired samples were used for analysis. The data seem to show more nematodes on control samples (7.4\%) than inside nests (1.5\%) but the McNemar test revealed no significant difference between the two samples $(P=0.103)$.

3.3. Fungi Isolation. Three fungi species (B. bassiana, $M$. anisopliae, and Paecilomyces sp.) were found both inside ant nests and in the soil control samples. In some samples more than one fungi species was isolated (Table 3). From the 61 evaluated samples (nine were accidently lost), significant difference was found between the number of isolated entomopathogenic fungi inside ant nests $(3.3 \%)$ and control samples $(16.4 \%),(P=0.021)$ McNemar Test. B. bassiana and $M$. anisopliae were found inside ant nests as frequently as in soil control samples $(P=0.096)$. Paecilomyces sp. was

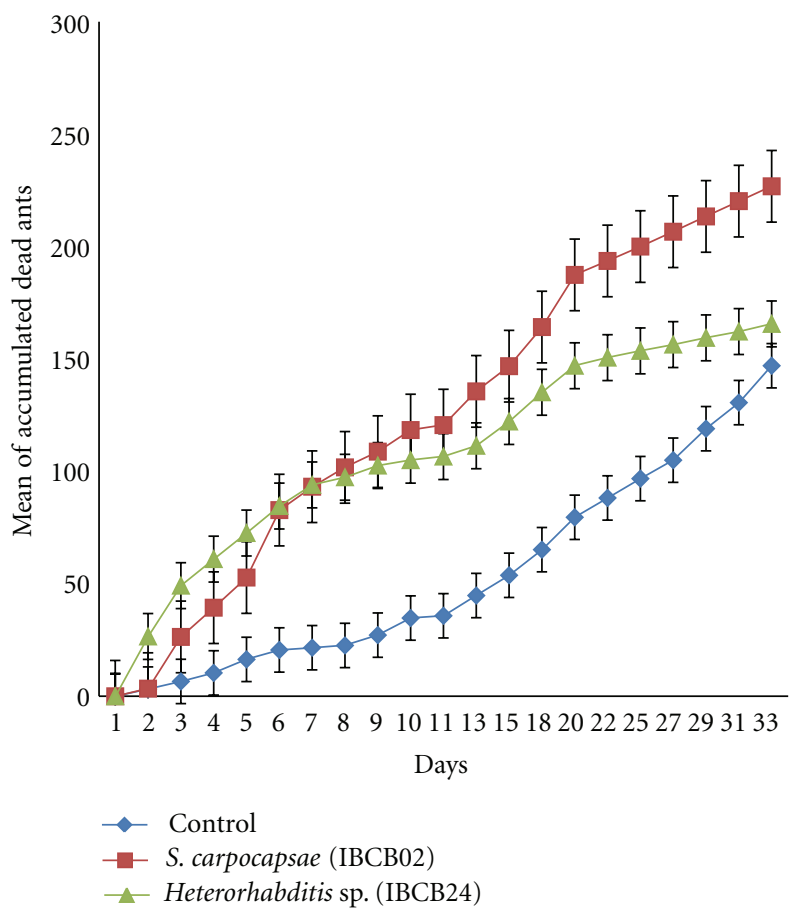

FIGURE 1: Mean of cumulative mortality of Monomorium floricola workers treated with entomopathogenic nematodes from five experimental colonies.

more common in soil control samples than inside ant nests $(P=0.021)$ (Table 4$)$.

\subsection{Susceptibility of Monomorium floricola to Entomopathogens in Laboratory Conditions}

3.4.1. Susceptibility to Entomopathogenic Nematodes. S. carpocapsae (IBCB 02) and Heterorhabditis sp. (IBCB 24) caused M. floricola worker mortality (Figure 1). The Tukey Test showed that ant worker mortality in nematode-treated tests was significantly higher than control worker mortality for the two tested nematodes (treatment: $P=0.005$, time: $P<0.001$, and interaction: $P=0.024$ ).

The nematode IBCB 24 caused higher M. floricola worker mortality in the first six days after nematode application. After this period, the two tested nematodes showed a similar mortality curve. The observed mortality curve on control 
TABLE 3: Frequency of isolated fungi from ant nests and soil control samples.

\begin{tabular}{|c|c|c|}
\hline & Frequency & Percentage \\
\hline \multicolumn{3}{|c|}{ Isolated fungi from ant nests } \\
\hline B eauveria bassiana only & 3 & $4.8 \%$ \\
\hline Metarhizium anisopliae only & 6 & $9.7 \%$ \\
\hline Metarhizium anisopliae + , Beauveria bassiana & 1 & $1.6 \%$ \\
\hline Paecilomyces sp. +, Metarhizium anisopliae & 1 & $1.6 \%$ \\
\hline Paecilomyces sp. + Metarhizium anisopliae & 2 & $3.2 \%$ \\
\hline Paecilomyces sp. only & 9 & $14.5 \%$ \\
\hline Nothing found & 40 & $64.5 \%$ \\
\hline Total & 62 & $100 \%$ \\
\hline \multicolumn{3}{|c|}{ Isolated fungi from soil control samples } \\
\hline Beauveria bassiana only & 6 & $9.5 \%$ \\
\hline Beauveria bassiana + Paecilomyces sp. & 1 & $1.6 \%$ \\
\hline Beauveria bassiana + Metarhizium anisopliae & 1 & $1.6 \%$ \\
\hline Metarhizium anisopliae only & 5 & $7.9 \%$ \\
\hline Metarhizium anisopliae + Paecilomyces sp. & 1 & $1.6 \%$ \\
\hline Paecilomyces sp. Beauveria bassiana + Metarhizium anisopliae & 1 & $1.6 \%$ \\
\hline Paecilomyces sp. + Beauveria bassiana & 1 & $1.6 \%$ \\
\hline Paecilomyces sp., Metarhizium anisopliae & 2 & $3.1 \%$ \\
\hline Paecilomyces sp. + Metarhizium anisopliae + Beauveria bassiana & 1 & $1.6 \%$ \\
\hline Paecilomyces sp. only & 12 & $19 \%$ \\
\hline Nothing found & 32 & $50.8 \%$ \\
\hline Total & 63 & $100 \%$ \\
\hline
\end{tabular}

TABle 4: Isolation of Beauveria bassiana, Metarhizium anisopliae, and Paecilomyces sp. inside ant nests and in soil control samples.

\begin{tabular}{|c|c|c|c|c|}
\hline \multirow{2}{*}{ Beauveria bassiana isolation } & & \multicolumn{2}{|c|}{ Control } & \multirow{2}{*}{ Total } \\
\hline & & No & Yes & \\
\hline \multirow[t]{2}{*}{ NEST } & No & $50(82.0 \%)$ & $7(11.5 \%)$ & $57(93.4 \%)$ \\
\hline & Yes & $2(3.3 \%)$ & $2(3.3 \%)$ & $4(6.6 \%)$ \\
\hline Total & & $52(85.3 \%)$ & $9(14.8 \%)$ & $61(100 \%)$ \\
\hline \multirow{2}{*}{ Metarhizium anisopliae isolation } & & \multicolumn{2}{|c|}{ Control } & Total \\
\hline & & No & Yes & Iotal \\
\hline \multirow{2}{*}{ NEST } & No & $46(75.4 \%)$ & $5(8.2 \%)$ & $51(83.6 \%)$ \\
\hline & Yes & $5(8.2 \%)$ & $5(8.2 \%)$ & $10(16.4 \%)$ \\
\hline Total & & $51(83.6 \%)$ & $10(16.4 \%)$ & $61(100 \%)$ \\
\hline \multirow{2}{*}{ Paecilomyces sp. isolation } & & \multicolumn{2}{|c|}{ Control } & Total \\
\hline & & No & Yes & \\
\hline \multirow{2}{*}{ NEST } & No & $40(65.6 \%)$ & $10(16.4 \%)$ & $50(82.0 \%)$ \\
\hline & Yes & $2(3.3 \%)$ & $9(14.8 \%)$ & $11(18.0 \%)$ \\
\hline Total & & $42(68.9 \%)$ & $19(31.2 \%)$ & $61(100 \%)$ \\
\hline
\end{tabular}

treatments showed progressive growth along the 33 days of evaluation due to stress caused by laboratory manipulation (Figure 1).

In this study, ant workers did not show any signs of infection by nematodes, but immatures were infected in the first days after application. We did not confirm the death of workers that received nematode applications, however, no nematode was observed in the traps.

Despite mortality of adult $M$. floricola workers throughout the test, no reduction of the colony was noticed in any treatment. There was no reduction in the amount of brood and queens. Throughout the observation period, all forms of immature individuals (eggs, larvae, and pupae) were observed in all colonies, but there was no production of alates. This observation is probably not correlated with the application of nematodes, since the control and the rearing colonies, which originated the ant population for the treatments, also did not show any males or ergatoid gynes.

The experimental colonies did not reduce in size, and sometimes a small increase of individuals was observed. 
Grooming behavior was observed among workers that received nematode application. During the first evaluation days, the workers moved slower and constantly cleaned themselves. All treated groups showed an attempt to colony budding. Workers moved with the brood to the edges of the Petri dishes, leaving the center of the colony empty, probably due to a higher concentration of nematodes in this place.After attempted budding was observed, a new Petri dish was offered for all experimental colonies and they all moved to this new environment. Control colonies moved only half of the total brood, and workers, occupying both Petri dishes. Ant workers perceive the presence of nematodes and quickly move away healthy brood leaving only infected brood behind. There was not enough time for nematodes to infect ant individuals before they moved to other places free of nematodes.

After this period of evasion noticed in the first week of evaluation, the colonies showed no sign of infection. The ergatoid gynes continued oviposition and the colonies gradually increased in number of individuals. Dead workers remained distributed throughout the tray where colonies were kept and were not separated by live ant workers as usually happened with dead ants in the control colonies.

Behavioral responses, such as colony budding, show that the ants did suffer with nematode presence.

3.4.2. Susceptibility to Entomopathogenic Fungi. Both concentrations of $B$. bassiana isolated from ant nests ( $\mathrm{Bb} 25$ $1 \times 10^{7}$ and $\left.\mathrm{Bb} 251 \times 10^{8}\right)$ and from the Entomopathogenic Collection (Bb $661 \times 10^{7}$ and Bb $661 \times 10^{8}$ ) caused higher M. floricola workers death in both tested concentrations (Figure 2). Ant mortality caused by the two $B$. bassiana isolates was significantly higher than the control and the other tested fungi (treatment: $P<0.001$, time effect: $P<0.001$, and interaction: $P<0.001$ ) over the 30-day evaluation.

In the present study, mortality of $M$. floricola workers treated with Paecilomyces sp. P 405 (from the Entomopathogen Collection) was considerably high. Similar observation was not obtained from applications with Paecilomyces sp. isolated from ant nests. None of the $M$. anisopliae isolates in any concentrations killed significant numbers of workers in our experiment. None of the $M$. anisopliae isolates in any concentrations killed workers in our experiment (Figure 2).

During the application of the fungal suspensions $M$. floricola workers were also crowded in the center of the Petri dishes. This behavior may have prevented large doses of fungal spores on a number of individuals, including the brood.

We observed that mortality of workers started to increase on the third day after fungal applications. Evaluation of fungal growth on the $M$. floricola worker cadavers also confirmed the high mortality due to fungi contamination from the third day. The highest confirmed mortality rates were obtained from the first to the tenth day after application. After this period the workers continued to die in greater

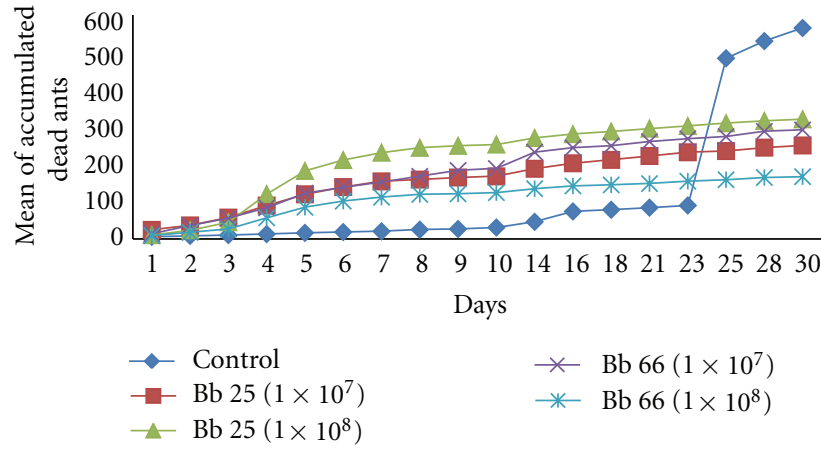

(a)

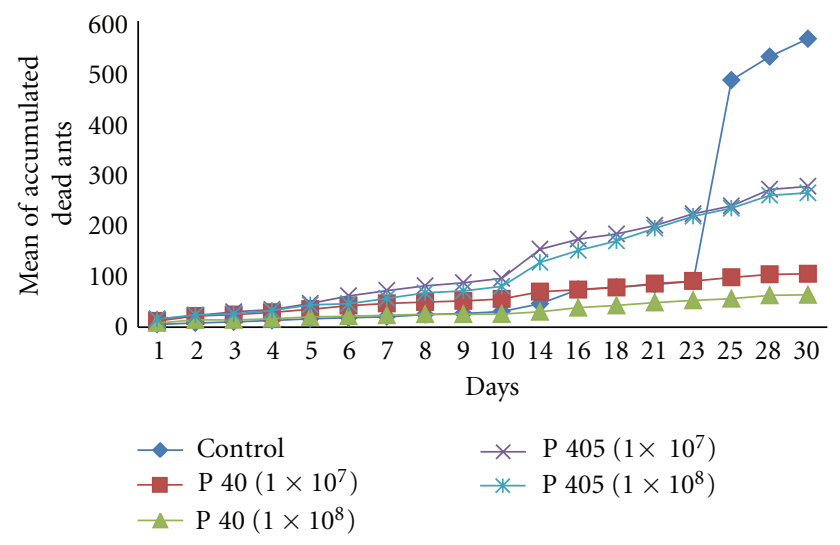

(b)

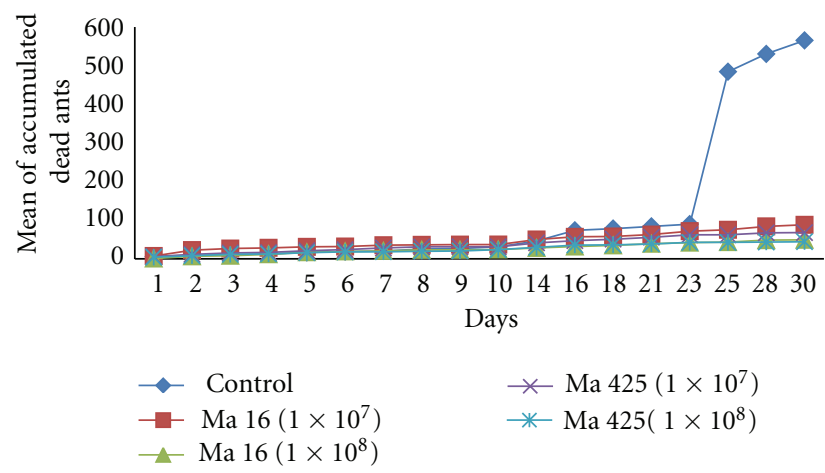

(c)

FIGURE 2: Mean of cumulative mortality of Monomorium floricola workers, from five experimental colonies, submitted to the application of entomopathogenic fungi in different concentrations. Bb: Beauveria bassiana; P: Paecilomyces sp. Ma: Metarhizium anisopliae.

numbers than those of the control colonies, but fungal growth on cadavers was no longer observed.

During the experiment, most colonies did not increase in size, but there was no apparent decrease. Treated workers constantly cleaned themselves and moved slowly, but there was no decrease in foraging. There was no decrease in the amount of brood and queens in any colony. All immature stages were present but we did not observe the presence of alates, including the control colonies. 
During the first days of evaluation, workers cleaned themselves probably trying to get rid of the fungal conidia. Unlike colonies treated with nematodes, no colony budding was observed when ants were treated with entomopathogenic fungi. Uninfected workers did not separate dead bodies maybe to avoid colony contamination.

\section{Discussion}

4.1. Entomopathogens Isolated from Invasive Ants and Tests of Their Pathogenicity. In this work entomopathogens were collected from Solenopsis spp. as other authors have already registered. Entomopathogens are commonly found on ant workers [16-18] and several of them have been collected in South American regions and proved as pathogenic to ants, especially Solenopsis $[19,20]$. B. bassiana has been isolated from Atta sexdens rubropilosa and Solenopsis workers [21]. M. anisopliae and B. bassiana were isolated from S. invicta and A. sexdens piriventris $[22,23]$ in areas with no plant cover.

4.2. Susceptibility to Entomopathogenic Nematodes. The use of the nematodes S. carpocapsae and Heterorhabditis sp. for ant control has been successfully reported by several researchers [6, 24-27]. Poole [24] observed that Solenopsis sp. brood and alates were susceptible to a $S$. carpocapsae isolate when confined in small bottles containing infected soil. However, the adult workers were not much susceptible to their action. Drees et al. [6] also reported that nematodes caused mortality of Solenopsis sp. larvae, pupae, and alate, although the adult workers were not susceptible to the nematode. Ant workers vigorously groomed the brood, alates and themselves when the nematode was present. This defensive behavior probably removes the nematodes and was also observed by us.

As our experimental colonies did not reduce in size, and we could observe a small increase of individuals, it can be explained as an attempt by the colonies to recover from the control action. Zarzuela [28] also observed a recovery of the colonies of the same species in response to applications of chemical insecticides. If there is a disruption, whether chemical or biological, the ants tend to respond by increasing the number of individuals. Self-grooming and allogrooming, behaviors that we have observed, may impede or facilitate the spread of infection and disease according to Oi and Pereira [29]. While grooming among individuals of the colony may reduce infection by removal of the pathogen, it may also cause the spread of the disease, since the transfer of this pathogen can occur among individuals. The spread of pathogens as a result of grooming has not been observed in ants, but it is well documented on termites [30]. Drees et al. [6] reported that continuous brood, alate, or selfcleansing by workers of Solenopsis sp. after exposure of Steinernema and Heterorhabditis is an attempt to remove these nematodes.

Ant behavior changes caused by nematodes were also observed by other authors, besides grooming and colony recovery. Jouvenaz et al. [31] reported that $S$. invicta colonies displaced infected soil after treatment with Steinernema and
Heterorhabditis. Drees and colleagues [6] observed that a significant number of ants abandoned their colonies when they received nematodes, forming new nests nearby. Budding after nematode treatment limits its use to control ant colonies in the field and we could observe such behavior in our experimental colonies.

4.3. Susceptibility to Entompathogenic Fungi. Many studies have reported the efficacy of B. bassiana in controlling ants. Alves and Gómez [21] observed high infectivity of this fungus on Atta sexdens rubropilosa. Pereira and colleagues [32] used the strain 447 of B. bassiana on workers of S. invicta and obtained $100 \%$ infection and mortality. Also for this same ant species, Stimac et al. [12] reported that almost 90\% colonies treated with B. bassiana were killed. In 1995, KelleyTunis et al. [33] described a higher mortality of Camponotus pennsylvanicus workers when exposed to B. bassiana than when exposed to M. anisopliae.

In our study, Paecilomyces sp. P 405 killed a number of M. floricola workers but the same fungi isolated from ant nests were not efficient. Loureiro and Monteiro [34] applied $P$. farinosus in several concentrations on A. sexdens sexdens and reported $80 \%$ mortality of ant soldiers in the first four days after application.

Besides, M. anisopliae did not kill significant numbers of M. floricola ant workers, similar studies have demonstrated successful application of this fungus on ants [21, 23, 34-37]. Nevertheless, fungi are less effective when applied to colonies $[35,36]$, as occurred in this study. This decrease in efficacy has been attributed to a number of behaviors and chemical factors that ants exhibit [37].

A more effective alternative considered by several authors [37-41] is bait formulation in order to make the ants carry the fungus to the interior of the colonies. Although sometimes ants may perceive the presence of entomopathogens, these can be masked by the addition of attractive food $[38,39]$.

Formulations may play important role in fungal efficacy against ants. Silva and Diehl-Fleig [42] were successful when using spore suspensions of $M$. anisopliae. They recorded a decline of $A$. sexdens piriventris foraging for six days after application. However, direct application to the nests, is time consuming and impractical as a viable strategy in large areas $[39,42]$.

In the study conducted by Stimac and colleagues [12], the highest concentrations of $B$. bassiana conidia resulted in a higher mortality of $S$. invicta. The authors emphasize two important points in order to determine the optimal dose for higher ant mortality: application method and ant behavior. The authors observed that, when a large number of workers receive a fungal application, the ants tend to form a ball of bodies. It is difficult to reach all the individuals with the suspension of fungi. Due to cuticle composition, conidial suspensions are repelled by the mass of ants. Thus, the workers remaining in the center of the ant mass can not receive the same amount of treatment as the ants at the periphery of the ant mass. 
We observed that mortality of workers started to increase on the third day after fungal applications. Increased mortality curves from the third day after entomopathogenic fungi application has been described since the initial studies of Stimac et al. [12, 19] and Alves et al. [20]. Such results are related to the necessary time for adhesion, germination, and growth of fungi before the insect death [43].

During the experiment, most colonies did not increase in size, but there was no apparent decrease. As with nematodes experiment, grooming behavior removes conidia or other fungal particles from the ant cuticle before infection occurs, and consequently reduces the infection rate of the entire colony. Observations under electron microscopy of $S$. invicta inoculated with $B$. bassiana conidia demonstrated the removal of conidia from the adult and larval integuments [29] and Sánchez-Peña and Thorvilson [44] inferred that self-grooming prevented ant infection by Conidiobolus conidia.

As nematodes, fungi can be promising alternatives for the control of urban ants. However, further studies should be conducted to determine the concentrations and application methods that can avoid the various defense behaviors of ants.

\section{Acknowledgment}

The authors thank the anonymous referees for their suggestions and corrections.

\section{References}

[1] O. C. Bueno and A. E. C. Campos-Farinha, "As formigas domésticas," in Insetos e Outros Invasores de Residência, F. A. M. Mariconi, Ed., pp. 135-180, Fealq, Piracicaba, Brazil, 1999.

[2] A. E. Hajek et al., "Invasive arthropods and approaches for their microbial control," in Use of Microbes for Control and Erradication of Invasive Arthropods, A. E. Hajek et al., Ed., pp. 3-15, Springer Science Business Media B.V., 2009.

[3] A. Batista-Filho, Controle biologico: Alternativa Para uma Agricultura Sustentável, Boletim Técnico do Instituto Biológico, Controle Biológico de Insetos e Ácaros, São Paulo, Brazil, 2006.

[4] R. M. Pereira and J. L. Stimac, "Biocontrol options for urban pest ants," Journal of Agricultural and Urban Entomology, vol. 14, no. 3, pp. 231-248, 1997.

[5] D. P. Jouvenaz, "Natural enemies of fire ants," Florida Entomologist, vol. 66, pp. 111-121, 1983.

[6] B. M. Drees, R. W. Miller, S. B. Vinson, and R. Georgis, "Susceptibility and behavioral response of red imported fire ant (Hymenoptera: Formicidae) to selected entomogenous nematodes (Rhabditida: Steinernematidae \& Heterorhabditidae)," Journal of Economic Entomology, vol. 85, no. 2, pp. 365370, 1992.

[7] D. P. Jouvenaz and W. R. Martin, "Evaluation of the nematode Steinernema carpocapsae to control fire ants in nursery stock," Florida Entomologist, vol. 75, pp. 148-151, 1992.

[8] R. M. Pereira and J. L. Stimac, "Transmission of Beauveria bassiana within nests of Solenopsis invicta (Hymenoptera: Formicidae) in the laboratory," Environmental Entomology, vol. 21, no. 6, pp. 1427-1432, 1992.

[9] R. M. Pereira, S. B. Alves, and J. L. Stimac, "Growth of Beauveria bassiana in fire ant nest soil with amendments," Journal of Invertebrate Pathology, vol. 62, no. 1, pp. 9-14, 1993.
[10] S. R. Sánchez-Peña and H. G. Thorvilson, "Two fungi infecting red imported fire ant founding queens from Texas," Southwestern Entomological, vol. 17, pp. 181-182, 1992.

[11] S. R. Siebeneicher, S. B. Vinson, and C. M. Kenerley, "Infection of the red imported fire ant by Beauveria bassiana through various routes of exposure," Journal of Invertebrate Pathology, vol. 59, no. 3, pp. 280-285, 1992.

[12] J. L. Stimac, S. D. Alves, and R. M. Pereira, "Mortality in laboratory colonies of Solenopsis invicta (Hymenoptera:Formicidae) treated with Beauveria bassiana (Deuteromycetes)," Journal of Economic Entomology, vol. 86, no. 4, pp. 1083-1087, 1993.

[13] G. F. White, "A method for obtaining infective nematode larvae from cultures," Science, vol. 66, no. 1709, pp. 302-303, 1927.

[14] L. Jacob, Seleção de ingredientes ativos para o controle de formigas urbanas [M.S. thesis], Instituto de Biociências da Universidade Estadual Paulista, 2002.

[15] S. B. Alves, "Fungos entomopatogênicos," in Controle Microbiano de Insetos, S. B. Alves, Ed., pp. 289-381, Fealq, Piracicaba, Brazil, 1998.

[16] H. C. Evans, "Natural control of arthropods, with special reference to ants (Formicidae), by fungi in the tropical high forest of Ghana," Journal of Applied Ecology, vol. 11, pp. 37-49, 1974.

[17] R. A. Samsom, H. C. Evans, and J. P. Latgé, Atlas of entomopathogenic fungi, Springer, Berlin, Germany, 1988.

[18] H. C. Evans, "Mycopathogens of insects in epigeal and aerial habitats," in Insect-Fungus Interactions, N. Wilding, N. M. Collins, P. M. Hammond, and J. F. Weber, Eds., pp. 205-238, Academic Press, London, UK, 1989.

[19] J. L. Stimac, S. D. Alves, and M. T. V. Camargo, "Suscetibilidade de Solenopsis spp. à diferentes espécies de fungos entomopatogênicos," Anais da Sociedade Entomológica do Brasil, vol. 16, pp. 377-387, 1987.

[20] S. B. Alves, J. L. Stimac, and M. T. V. Camargo, "Suscetibilidade de Solenopsis invicta Buren e S. saevissima Fr. Smith a isolados de Beauveria bassiana (Bals.) Vuill," Anais da Sociedade Entomológica Brasileira, vol. 17, pp. 379-387, 1988.

[21] S. B. Alves and S. Gómez, "Virulência do Metarhizium anisopliae e Beauveria bassiana para duas castas de Atta sexdens rubropilosa," Poliagro, vol. 5, pp. 1-9, 1983.

[22] G. E. Allen and W. F. Buren, "Microsporidian and fungal diseases of Solenopsis invicta Buren in Brazil," Journal of the New York Entomological Society, vol. 82, pp. 125-130, 1974.

[23] E. Diehl-Fleig, M. E. Silva, and M. R. M. Pacheco, "Testes de patogenicidade dos fungos Beauveria bassiana e Metarhizium anisopliae em Atta sexdens piriventris (Santschi, 1919) em diferentes temperaturas," Ciência e Cultura, vol. 40, no. 11, pp. 1103-1105, 1988.

[24] M. A. Poole, Survey and control efficacy of endoparasites of Solenopsis richteri Forel and S. invicta Buren in Mississipi [Ph.D. Dissertation], Mississippi State University, Starkville, Miss, USA, 1976.

[25] C. Laumond, H. Mauléon, and A. Kermarrec, "Données nouvelles sur le spectre d'hôtes et le parasitisme du nématode entomophage Neoaplectana carpocapsae," Entomophaga, vol. 24, no. 1, pp. 13-27, 1979.

[26] E. C. Quattlebaum, Evaluation of fungal and nematode pathogens to control the red imported fire ant, Solenopsis invicta Buren [Ph.D. Dissertation], Clemson University, Clemson, South Carolina, 1980.

[27] D. P. Jouvenaz, "Approaches to biological control of fire ants in the United States," in Applied Myrmecology: A World 
Perspective, R. K. Vander Meer, K. Jaffe, and A. Cedeno, Eds., pp. 620-627, Westview Press, Boulder, Colo, USA, 1990.

[28] M. F. M. Zarzuela, Controle químico de Monomorium floricola por meio de produtos microencapsulados [M.S. Dissertation], Instituto de Biociências, Universidade Estadual Paulista, 2005.

[29] D. H. Oi and R. M. Pereira, "Ant behaviour and microbial pathogens (Hymenoptera: Formicidae)," Florida Entomologist, vol. 76, no. 1, pp. 63-75, 1993.

[30] K. R. Kramm, D. F. West, and P. G. Rockenbach, "Termite pathogens: transfer of the entomopathogen Metarhizium anisopliae between Reticulitermes sp. termites," Journal of Invertebrate Pathology, vol. 40, no. 1, pp. 1-6, 1982.

[31] D. P. Jouvenaz, C. S. Lofgren, and R. Miller, "Steinernematid nematode drenches for control of fire ants, Solenopsis invicta, in Florida," Florida Entomologist, vol. 73, no. 1, pp. 190-193, 1990.

[32] R. M. Pereira, J. L. Stimac, and S. B. Alves, "Soil antagonism affecting the dose - response of workers of the red imported fire ant, Solenopsis invicta, to Beauveria bassiana conidia," Journal of Invertebrate Pathology, vol. 61, no. 2, pp. 156-161, 1993.

[33] K. K. Kelley-Tunis, B. L. Reid, and M. Andis, "Activity of entomopathogenic fungi in free-foraging workers of Camponotus pennsylvanicus (Hymenoptera: Formicidae)," Journal of Economic Entomology, vol. 88, no. 4, pp. 937-943, 1995.

[34] E. S. Loureiro and A. C. Monteiro, "Patogenicidade de três fungos entomopatogênicos a soldados de Atta sexdens (Linnaeus, 1758) (Hymenoptera:Formicidae)," Revista Árvore, vol. 29, pp. 553-561, 2005.

[35] A. Kermarrec and M. Decharme, "Ecopathological aspects in the control of Acromyrmex octospinosus Reich (Form., Attini) by entomophagous fungi," in Biology of Social Insect, M. D. Breed, C. D. Michener, and H. E. Evans, Eds., Westview Press, Boulder, Colo, USA, 1982.

[36] A. Kermarrec, G. Febuay, and M. Decharme, "Protection of leaf-cutting ants from biohazards: is there future for microbiological control?" in Fire Ants and Leaf-Cutting AntsBiology and Management, C. S. Lofgren and R. K. V. Meer, Eds., pp. 339-356, Westview Press, 1986.

[37] D. B. Jaccoud, W. O. H. Hughes, and C. W. Jackson, "The epizootiology of a Metarhizium infection in mini-nests of the leaf-cutting ant Atta sexdens rubropilosa," Entomologia Experimentalis et Applicata, vol. 93, no. 1, pp. 51-61, 1999.

[38] M. C. Blowers, C. W. Jackson, and J. J. Knapp, "Effect of composition of alginate granules on their potencial as carriers of microbial control agents against the leaf-cutting ant Atta sexdens," in Biology and Evolution of Social Insects, J. Billen, Ed., pp. 145-151, Leuven University Press, 1992.

[39] A. Specht, E. Diehl-Fleig, and M. E. Silva, "Atratividade de iscas de Beauveria bassiana (Bals.) Vuill. a formiga do gênero Acromyrmex (Hymenoptera: Formicidae)," Anais da Sociedade de Entomologia do Brasil, vol. 23, pp. 99-104, 1994.

[40] E. Diehl-Fleig and M. E. Lucchese, "Reações comportamentais de operárias de Acromyrmex striatus (Hymenoptera: Formicidae) na presença de fungos entomopatogêncios," Revista Brasileira de Entomologia, vol. 35, pp. 101-107, 1991.

[41] D. F. Williams, D. H. Oi, S. D. Porter, R. M. Pereira, and J. A. Briano, "Biological control of imported fire ants (Hymenoptera: Formicidae)," American Entomologist, vol. 49, pp. 150-163, 2003.

[42] M. E. Silva and E. Diehl-Fleig, "Avaliação de diferentes linhagens de fungos entomopatogênicos para o controle da formiga Atta sexdens piriventris (Santschi Hymenoptera:
Formicidae)," Anais da Sociedade de Entomologia do Brasil, vol. 23, pp. 99-104, 1988.

[43] S. B. Alves, Controle Microbiano de Insetos, Editora Manole, São Paulo, Brazil, 1986.

[44] S. R. Sánchez-Peña and H. G. Thorvilson, "Effect of longterm cryogenic storage and conidial suspending agents on the virulence of Beauveria bassiana toward Solenopsis invicta," Journal of Invertebrate Pathology, vol. 65, no. 3, pp. 248-252, 1995. 

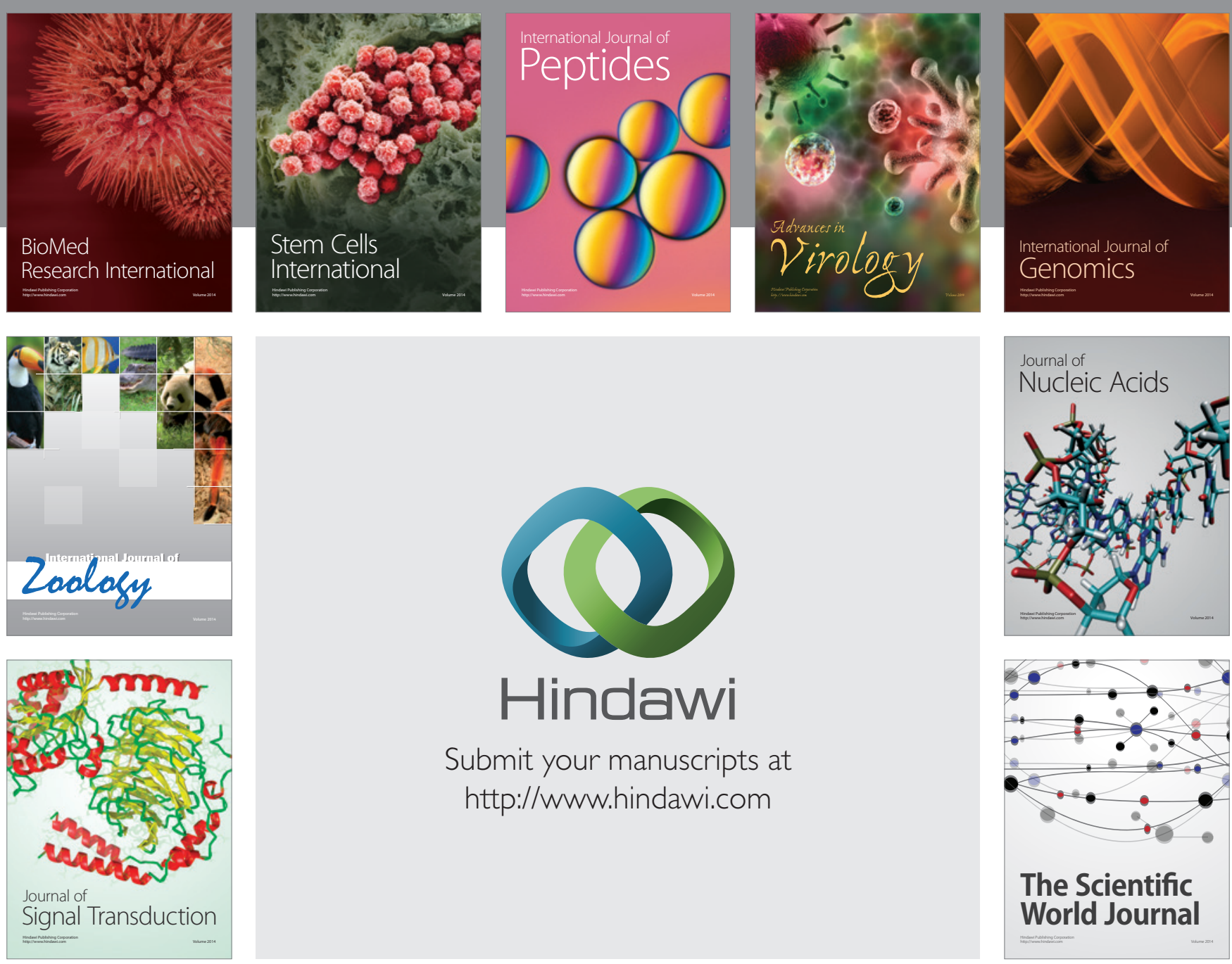

Submit your manuscripts at

http://www.hindawi.com
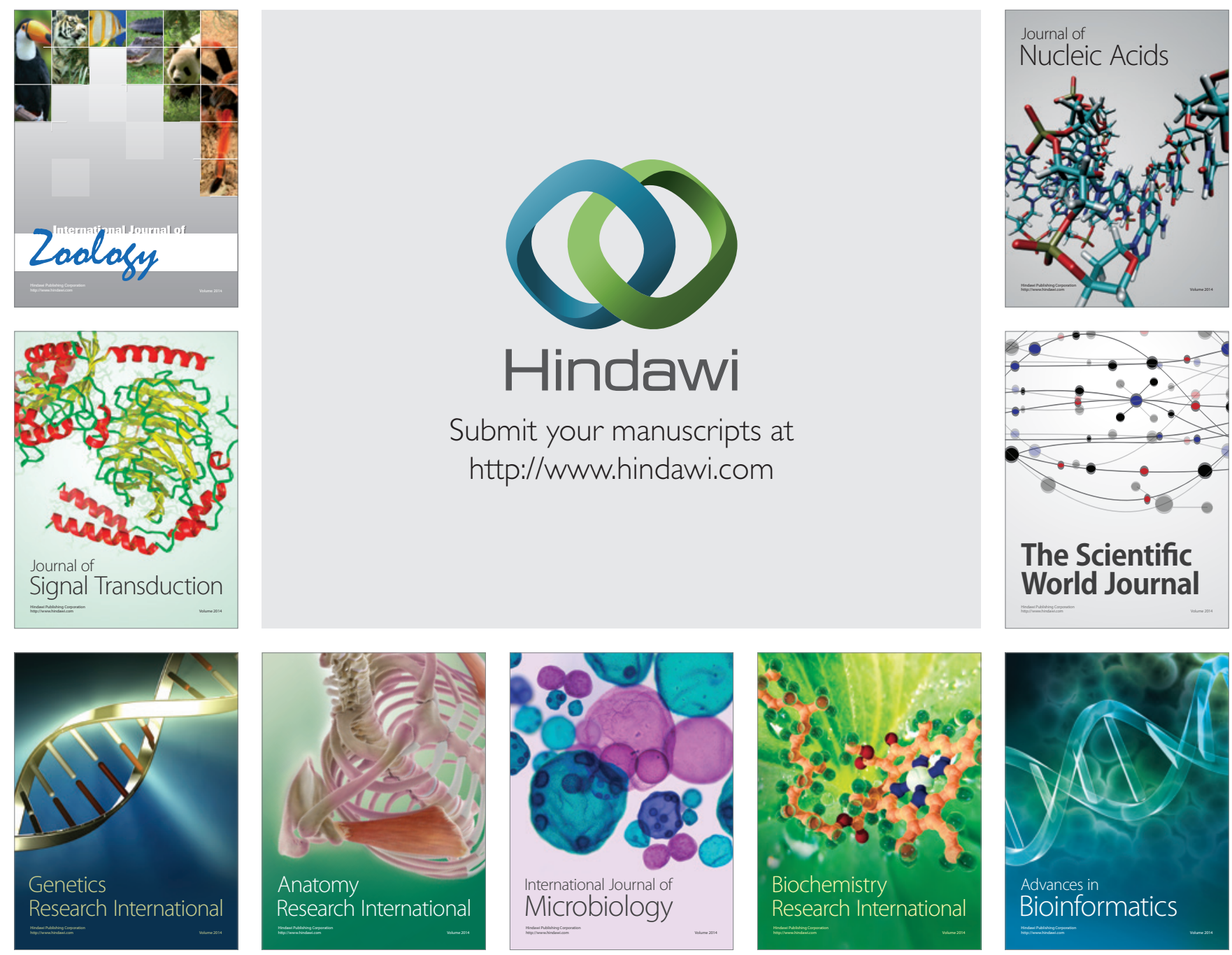

The Scientific World Journal
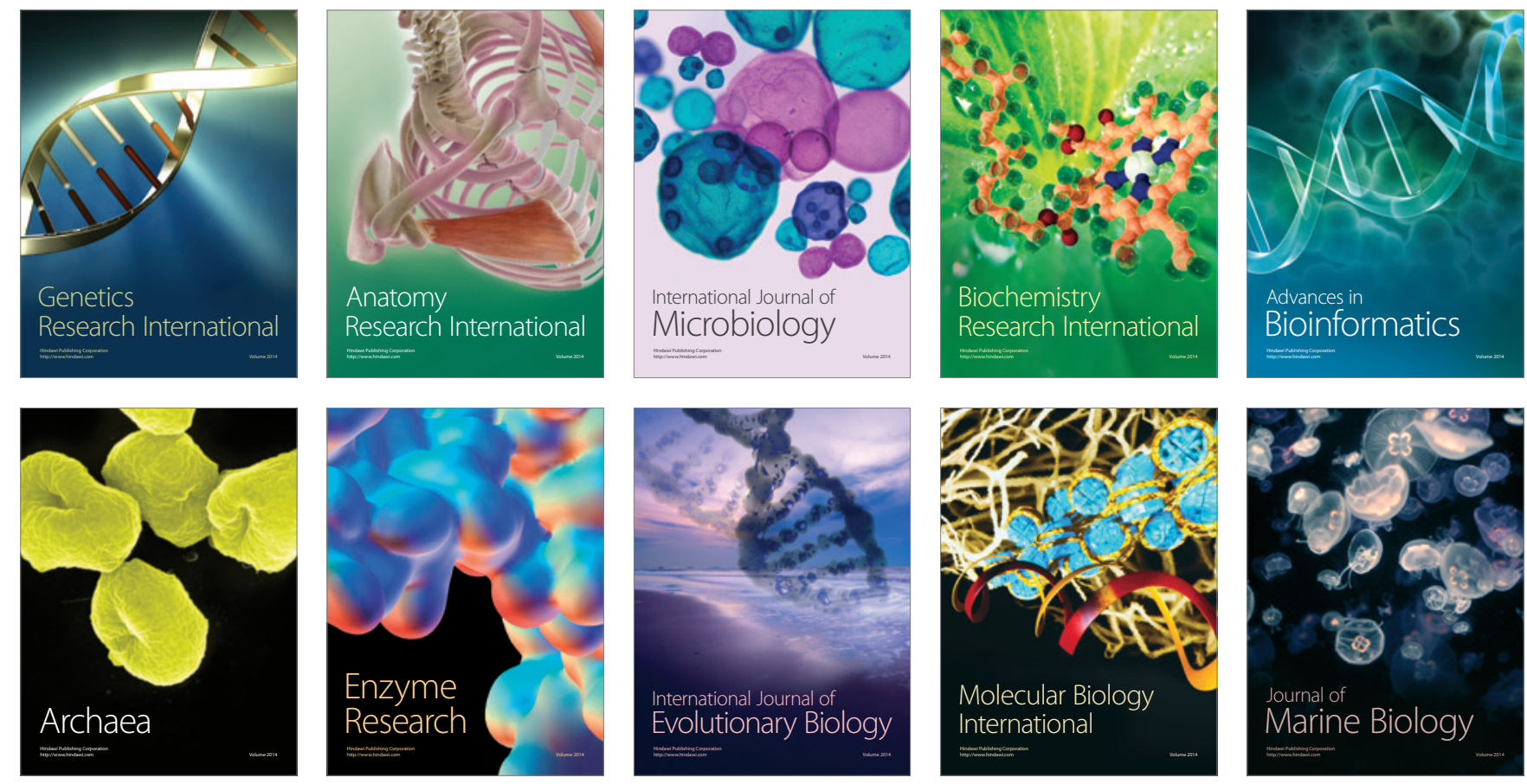